PERINATAL LESSONS FROM THE PAST

\title{
Louise Bourgeois (1563-1636): royal midwife of France
}

\author{
P M Dunn
}

Arch Dis Child Fetal Neonatal Ed 2004;89:F185-F187. doi: 10.1136/adc.2003.037929

Louise Bourgeois was the first practicing midwife to write of her experience of childbirth and of women's problems. She did much to enhance the respect in which her craft was held. For 26 years she was midwife to the royal court. received 500 crowns and for each daughter 300 , to cover the two months of service during the confinement; in 1610 she was awarded an annual pension of 300 crowns (fig 1).

In 1609 Louise Bourgeois published her book on obstetrics describing herself as "The first woman practicing my art to take up the pen". This work, ${ }^{5}$ with further enlarged editions in 1617,1626 , and 1634, contributed much to the advancement of French midwifery. It helped to establish the craft as a profession worthy of the respect of male physicians and barber-surgeons. The text was prepared with a real desire to enhance the knowledge of midwifery and to ensure that women received appropriate care in childbirth. It was translated into German, Dutch, and English ${ }^{6}$ and had a considerable influence in those countries during much of the 17th century. Louise Bourgeois must have been an extraordinary person to have imposed her influence in the way she did in a man's world. The following extracts from her book provide examples of the advice she gave, though it must be acknowledged that some of it was interspersed with the beliefs of that time which would now be regarded as absurd.

\section{General advice to midwives ${ }^{3}$} sisted of a physician as chairman, two surgeons, and two midwives. The family moved soon after to the rue Saint-André-des-Arts, and in no time she had a large practice in the Latin Quarter. Her reputation grew as a skilled midwife and an educated woman of discernment and discretion who was both respected and well liked. ${ }^{1-3}$

In 1600 Henri IV married Marie de Medici, and the following year the royal couple were expecting their first child. The King wanted to employ the sage-femme Madame Dupuis to be the royal midwife. She had attended his late mistress Gabrielle d'Estrees, who unfortunately had died of puerperal convulsions after delivery in 1559 . However, Marie de Medici had other ideas and chose instead Louise Bourgeois, who had already successfully attended the confinements of a number of ladies of the Court. Between 1601 and 1610, in which year the King was assassinated, six children were born to Marie, all attended by Louise. Four of the deliveries were in Fontainbleu. First there was the dauphin and future Louis XIII of France, then Elizabeth, the future queen of Spain, next Christina of Savoy, then the duc d'Anjou and, finally, Henrietta Maria who became the wife of Charles I of England. There was a further baby boy who died in infancy. He had been born by the breech, and Louise gained much credit for managing the delivery without medical help. Later she described her whole royal midwifery experience in considerable detail. ${ }^{4}$ For each royal son she
"Your only task is to do things properly, and serve those who call you in, following their wishes, provided that those wishes do not harm them; if what they want might damage them, make it clear to them ... in order to

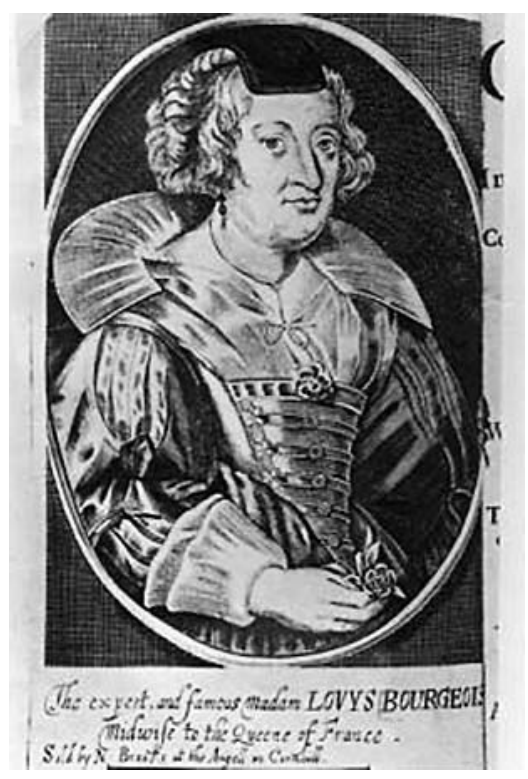

Figure 1 Louise Bourgeois, 1563-1636. 
persuade them to yield to reason. A midwife's gentleness produces better results than harshness." "And if she persists obstinately in wanting none of your advice, after you have gently given her to understand it is for the best, because it would be too painful afterwards-to give it to her. We must rescue what we can from a bad debt." "Above all, I advise you, whatever may happen, never seem to be at a loss; for there is nothing so unpleasant to witness as those households all at sixes and sevens. Never be surprised if something does not go well; because fear troubles the senses. Someone who is selfcontained and does not become upset, is able to set important matters right."

Louise Bourgeois' advice to midwives attending a normal labour emphasised the importance of patience, sympathy, gentleness, and service to the mother. The delivery should be supervised and organised with calm efficiency. Her approach was essentially non-interventionalist. Nature should be allowed to work unaided. Nothing should be done to hasten labour. Repeated manual examination of progress and efforts to widen and moisten the birth canal were to be avoided and the membranes were not to be broken.

\section{Advice on normal birth ${ }^{3}$}

\begin{abstract}
"You should wait for the time which God has ordained, and especially in normal births where there is no accident." "She (the midwife) must never make or allow others to make any noise in the room of a woman giving birth, during or after the birth." "(When) the suffering involved in giving birth is extreme ... accommodate (without harming her) the sick woman's humour ... You are called in with the sole task of helping and serving her." "I have often noticed that one of the most essential things for a woman in labour is to find the best position, for the comfort of the mother and child." "I am often so sorry to see women being constrained by mother or relative, trying, whatever I may say, to make them stay in one place ... so that it makes their condition twice as bad, and they are exhausted afterwards, that they cannot move." "The time of the birth having arrived, they did what their art demanded, which was, the child coming nicely, to reassure friends and family, keep her in a good position, have her eat as appropriate, keep her moderately warm, then help her to use her labour pains to bring everything to a happy conclusion."
\end{abstract}

\section{Position during childbirth}

While Bourgeois had experience of women delivering both in the standing and sitting positions, she preferred to keep women in bed unless the labour was too long, though she noted that this might be unhelpful in some cases. She wrote: ${ }^{3}$

\begin{abstract}
"A woman who wishes to keep about and can still do so until she is ready to give birth to the child, may be allowed to stand with legs apart, supported during the pains by two strong people, or she can have a low stool with a pillow on it, in front of a table, and can kneel on the pillow and put her arms on the table".
\end{abstract}

\section{Ligation of the umbilical cord $^{3}$}

"The umbilical cord should be ligated firmly, and if it be full of blood it ought to be emptied, for fear that this should turn into pus. It should be cut three finger-breadths below the ligature. If the cord is large and full of water and of winds, after the end has been wrapped in linen for half an hour it should be unwrapped and ligated afresh."

Bourgeois' advice on problem deliveries was also sound. She is credited with suggesting induction of premature labour in cases of contracted pelvis. For acute haemorrhage during labour she advocated manual extraction after podalic version, advice probably originating through her husband from Abroise Paré. Malpresentations, of which she listed 12 types, involved considerable internal manipulation by the midwife after placing the woman in a head down position. Manual extraction was recommended for retained placenta. However, she stressed the importance of flexibility and treating each case on its individual merits. Insisting that midwives should be acquainted with the anatomy of the uterus, she commented: "If she does not know this she may try to expel the uterus instead of the placenta, as has been done in this city."

\section{Prolapse of the cord}

Bourgeois depreciated rupture of the membranes for a number of reasons including the possibility of prolapse of the cord. When this happened she was aware of the danger to the fetus: "...because the cord gets cold and the circulation is interfered with and the respiration of the child stops. For while in the body of the woman he breathes through the cord because he is swimming in water, and he cannot like a fish without getting his mouth full of water." ${ }^{3}$ In management of this complication, she recommended that the woman be positioned with the head low and the hips elevated, that the cord be replaced, and that having greased the hand with butter, an attempt should be made to bring down the baby's legs and delivery be effected by gentle traction during a pain. If necessary, the cervix should first be dilated, first introducing the forefinger, then the thumb followed by the other fingers and the whole hand.

In 1627, aged 64, Louise Bourgeois attended the delivery of Duchess D'Orleans, wife of a prince of the blood. Sadly the Duchess died of puerperal peritonitis. The necropsy report signed by 10 learned doctors implied that Louise Bourgeois must have been in part to blame. To this she responded at once with a vigorous Apologie ${ }^{7}$ defending her record: "I have practiced my profession now for fully thirty-four years, faithfully, diligently, and honourably, and acquired not only a good certificate, after various examinations, but have also written books treating on this subject, which have been printed and published in several editions and were translated into foreign languages, for which trouble many noted physicians have rendered me thanks and have gladly confessed that they were of great use to humanity." It is clear that there was considerable professional rivalry between Louise and the physicians, in particular Guillemeau and Honore.

Martin Boursier died in 1632 and Louise three years later in 1636 at the age of 73 years. She had served the royal family and court for 26 years. Of her three children, the eldest, Francoise, married René Chartier, physician in ordinary to Henri IV and later physician to Henrietta Maria, wife of Charles I of England. Their son Jean in turn later became physician to Louis XIII. Martin and Louise's second child, a son, became an apothecary, while their second daughter became a midwife and married a physician.

\section{REFERENCES}

1 Robb H. Remarks on the writings of Louyse Bourgeois. Bull Johns Hopkins Hosp 1893;4:75-81.

2 Cutter IS, Viets HR. A short history of midwifery. Philadelphia: WB Saunders Co, 1964. 
3 Perkins W. Midwifery and medicine in early modern France: Louise Bourgeois. Exeter: University of Exeter Press, 1996.

4 Allport WH. Louise Bourgeois. An old midwife's tale. Am J Obstet 1912;65:820-51.
5 Bourgeois L. Observations diverses sur la sterilité perte de fruict foecondité accouchements et maladies des femmes et enfants nouveaux naiz. Paris, 1609.

6 Bourgeois L. The complete midwives' practice enlarged. 1659.

7 Bourgeois L. Apologie coutre le rapport des médecins. Paris, 1627.

\section{PostScript}

\section{LETTERS}

\section{Neonatal necrotising enterocolitis and perinatal exposure to co-amoxyclav}

Two recent studies have reported an association between antenatal exposure to coamoxyclav, either alone or in combination with erythromycin, and neonatal necrotising enterocolitis (NEC). ${ }^{12}$ Based on the analyses of secondary outcomes in these studies, the authors raised concerns about the use of coamoxyclav antenatally and recommended further investigation of its use in the neonatal period.

We have completed a case-control study designed to test the hypothesis that perinatal exposure to co-amoxyclav is associated with an increased risk of NEC. During a 17 year period (1983-2000), 32 cases of NEC were diagnosed in preterm infants born to mothers inbooked at Liverpool Women's Hospital. Of these, 17 were diagnosed at laparotomy, 12 had classical radiological features, and in three the diagnosis was made on clinical grounds alone. Two gestation matched controls were selected for each index case. Information on potentially relevant perinatal variables, including antenatal and postnatal exposure to co-amoxyclav, were collected from maternal and infant case notes.

Infants who developed NEC tended to be lighter at birth (median birth weight 853 (interquartile range (IQR) 717-1248) g v 1037 (IQR 779-1613)g in controls, $\mathrm{p}=0.065)$ and were more often delivered after absent or reversed flow identified on umbilical artery Doppler studies $(\mathrm{p}=0.007)$. Postnatally, Gram negative septicaemia preceding NEC was significantly more common in cases than controls $(p=0.005)$. However, the frequency of perinatal exposure to coamoxyclav was similar in both groups (table 1).

In summary, there is no evidence from this study of a link between perinatal exposure to co-amoxyclav and NEC. Our findings do not support the hypothesis that treatment with co-amoxyclav is causally associated with the development of NEC.

\section{A Al-Sabbagh, S Moss, N Subhedar}

Correspondence to: Dr Subhedar, NICU, Liverpool Women's Hospital, Crown Street, Liverpool L8 7SS, UK; nvsubhedar_lwh@yahoo.com

doi: $10.1136 /$ adc. 2002.022731

\section{References}

Kenyon SL, Taylor DJ, Tarnow-Mordi W (ORACLE Collaborative Group). Broad-spectrum antibiotics for spontaneous preterm labour: the ORACLE II randomised trial. Lancet 2001;357:989-94.

2 Kenyon SL, Taylor DJ, Tarnow-Mordi W ORACLE Collaborative Group. Broad-spectrum antibiotics for preterm, prelabour rupture of fetal membranes: the ORACLE I randomised trial. Lancet 2001;357:979-88.

\section{Birth weight of Chinese babies born in Italy}

Fok et al ${ }^{1}$ note that the birth weight (BW) of the Chinese neonates they studied is lower than that of babies born in some western countries and state that a genuine genetic predisposition exists leading to the smaller size of Chinese infants.

In Tuscany, an Italian region with 3.4 million inhabitants, about $0.5 \%$ of the population are immigrants from the People's Republic of China. Since the early 1990s, Chinese immigrants in Tuscany have formed a stable, endogamic, culturally defined, and economically well integrated community. They receive the same full free medical care as Italian citizens

Using the registry of the Regional Cystic Fibrosis Neonatal Screening Programme, which covers $99.9 \%$ of the Region's neonates, ${ }^{2}$ we extracted the data for all the 4787 ethnic Chinese babies born in Tuscany from 1 July 1991 to 31 December 2002 to two ethnic Chinese parents. The forms that accompany the blood sample for the screening test are completed at birth by an obstetrician or nurse and contain the neonate's sex, BW, and gestational age (GA). We calculated the mean BW of the Chinese babies for each sex and GA starting from the 35th week (missing data: 638 babies). To avoid errors in estimates, we excluded as unlikely for GA those
BWs that were more than 1.5 interquartile ranges above the 75 th or below the 25th centile for each GA and sex.

Compared with native Tuscan newborns, ${ }^{4}$ Chinese babies born in Tuscany have a higher mean BW at almost all GAs; only at the 40th, 4lst, and 42nd weeks for boys and 42nd week for girls is the mean BW of the Chinese babies slightly lower, but not significantly so. Compared with those born in China, ${ }^{1}$ Chinese babies born in Tuscany have a higher mean BW at all GAs, except for the 42nd week (girls). The differences we found are in many cases statistically significant, despite the small size of our population.

Our data conflict with the hypothesis of Fok et al that Chinese newborns have a genetic predisposition to a smaller size than their white counterparts and suggest that, to explain the differences in BW they found, maternal and environmental factors should be taken into consideration.

F Festini, M F Reali, G Taccetti, T Repetto, $M$ de Martino

Cystic Fibrosis Centre of Tuscany, Meyer Hospital, University of Florence, Italy; filippo.festini@iol.it

doi: 10.1136/adc.2003.033332

\section{References}

1 Fok TF, So HK, Wong E, et al. Updated gestational age specific birth weight, crown-heel length, and head circumference of Chinese newborns. Arch Dis Child Fetal Neonatal Ed 2003:88:F229-36.

2 Marianelli L, Taccetti G, Campana S, et al. Neonatal screening of the Tuscan population for cystic fibrosis using immunoreactive trypsinogen test molecular analysis on blood spot samples and measurements of lactase activity on meconium. Proceedings of the 9th Telethon Scientific Convention Rimini, Italy, 12-14 November 2000. Rome: Telethon Foundation Italy, 2000: 488.

3 Tukey JW. Exploratory data analysis. Don Mills, Ontario: Addison-Wesley, 1977.

4 Festini F, Procopio E, Taccetti G, et al. Gestational age-specific birth weight percentiles of Tuscan newborns and temporal trends of birth weight and prematurity in Tuscany, 1991-2002. Proceedings of the Tuscan Conference of the Italian Society of Pediatrics, Montecatini, Italy, 7-8 March 2003. Montecatini, Italy: Italian Society of Paediatrics,

Tuscan Chapter, 2003:111.

\section{CORRECTION}

Table 1 Exposure of infants with necrotising enterocolitis (NEC) and controls to co-amoxyclav

\begin{tabular}{llll}
\hline & NEC $(\mathbf{n}=\mathbf{3 2})$ & Controls $(\mathbf{n}=64)$ & p Value* \\
\hline Antenatal exposure & 5 & 11 & 1.0 \\
Postnatal treatment & 19 & 30 & 0.25 \\
Any perinatal exposure & 20 & 34 & 0.38 \\
\hline
\end{tabular}

${ }^{*} \chi^{2}$ or Fisher's exact test. 